\title{
Discovery and material study of the missing feet part from Magritte's L'évidence éternelle of 1954
}

\author{
Catherine Defeyt $^{1^{*} \mathbb{D}}$, Francisca Vandepitte ${ }^{2}$, Elodie Herens ${ }^{1}$ and David Strivay ${ }^{1}$
}

\begin{abstract}
One of the two missing canvases from Lévidence éternelle of 1954, the one of the feet, has been discovered beneath a small woman portrait painted in 1958, La toile de Pénélope. Indeed, the underlying woman's feet revealed through the IRR and XRR images leave little doubt about the identity of the hidden composition. All the more so as the canvas dimensions perfectly match with the format ascribed to the feet part in the diagram Magritte made of the 1954 variant of Lévidence éternelle. This paper presents the main results of the material study conducted on La toile de Pénélope by means of non-invasive and complementary imaging and analytical techniques. Furthermore, it proposes a virtual colorized reconstruction of the hidden picture, built on the basis of the XRR and IRR images, the elemental information provided by the MA-XRF analysis, the Raman results and the microscope examination of the painting surface.
\end{abstract}

Keywords: Magritte, Painting, Non invasive

\section{Introduction}

In the framework of the project Magritte on practice (2015-2018), 50 oil paintings and 10 gouaches made by the artist between 1920 and 1967, and housed by the Magritte Museum (Royal Museums of Fine Arts of Belgium-RMFAB), have been investigated in situ by means of a mobile lab equipped with a large panel of non-invasive methods. The implemented imaging and analytical techniques are: infrared reflectography (IRR), X-ray radiography (XRR), high resolution visible and UV light photography, Raman spectroscopy (RS), digital microscopy, and scanning X-ray fluorescence (MA-XRF).

Amongst the axes of research developed in the project there was the discovery of double paintings. Indeed, David Sylvester pointed out the fact that Magritte routinely reused the canvas supports from previous paintings. A practice the author has correlated with the artist's financial difficulties, persisting until the 1940s [1]. The quantity and the quality of the overpainted compositions remain

\footnotetext{
*Correspondence: Catherine.Defeyt@uliege.be

${ }^{1}$ UR Art, Archéologie, Patrimoine, Université de Liège, 4000 Liege, Belgium

Full list of author information is available at the end of the article
}

outstanding issues. The specialists of the Belgian surrealist are then faced with a challenging task; the assessment of the importance and the significance of the lost works.

In that respect, the extended number of RMFAB paintings investigated through complementary imaging techniques has greatly increased the chances of discovering double paintings. Indeed, six double oil paintings have been discovered within the Brussels corpus $[2,3]$.

One of them is La toile de Pénélope (René Magritte Catalogue Raisonné (RMCR) n 893 [4], RMFAB inv. 11699), a small woman portrait executed in 1958, for which the IRR and XRR images revealed the presence of two woman's feet lying beneath the painting surface (Fig. 1a). The discovered feet have been rapidly identified as part of the third and last variant Magritte made of L'évidence éternelle in 1954 (RMCR $\mathrm{n}^{\circ} 807$ [4]).

This paper presents an overview of the results obtained for La toile de Pénélope, which includes the current picture and the feet lying underneath. The combination of imaging and analytical methods permitted collection of substantial information about the appearance of the hidden composition. The present paper proposes a virtual colorized reconstruction of the lost fifth part from Lévidence éternelle, on the basis of these outcomes. 

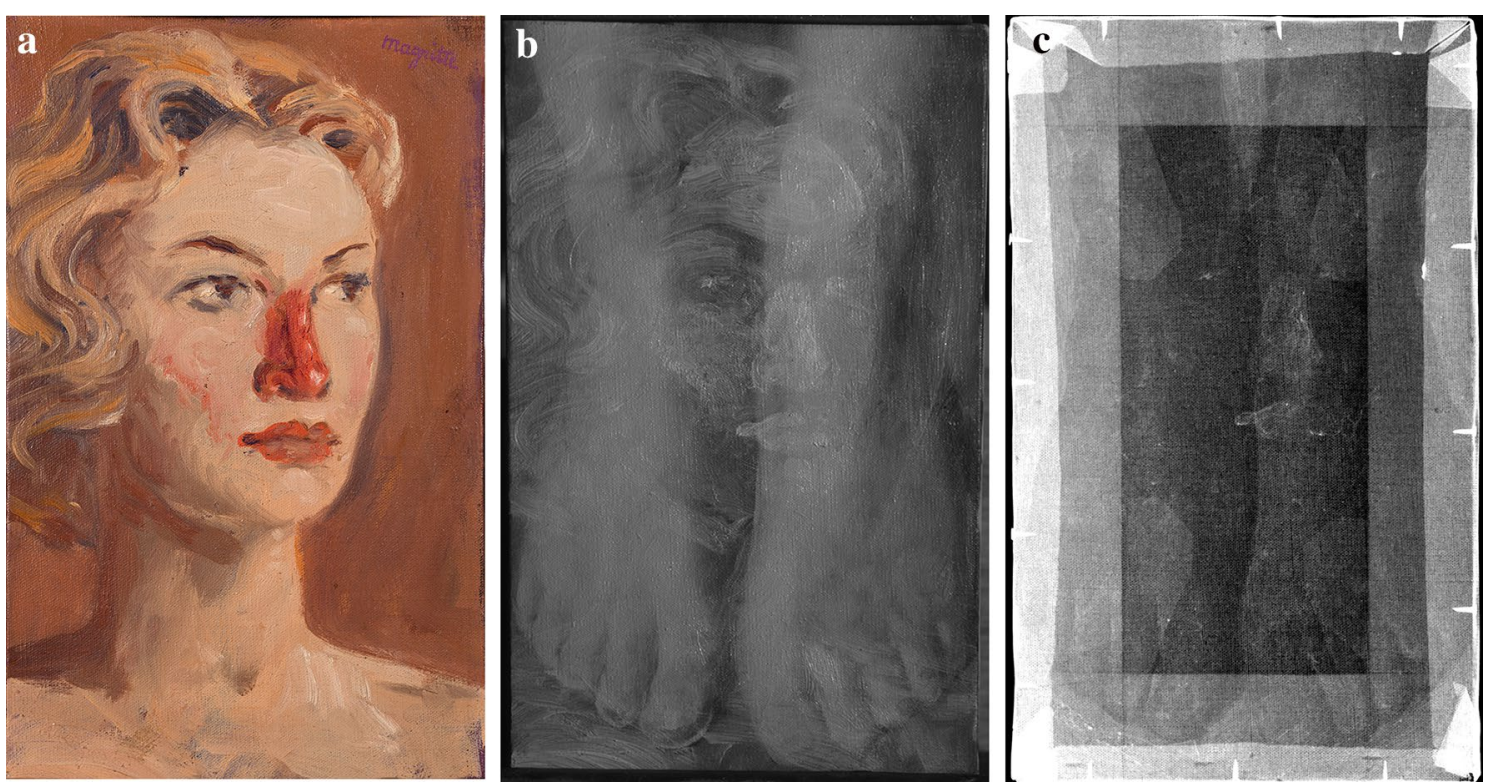

Fig. 1 La toile de Pénélope La toile de Pénélope, 1958, oil on canvas, 24.6 × 14.8 cm, RMCRn 893, RMFAB inv. 11699 oCharly Herscovici, Belgium. a visible image, $\mathbf{b}$ IRR image, $\mathbf{c}$ XRR image. The IRR and XRR images unveiled the presence of two woman's feet beneath the current picture

\section{Experimental}

A high-resolution photographic documentation was first gathered. The full size images in visible light and under ultra violet light have been acquired by using the homemade scanning system of the CEA [5] and a D7500 Nikon camera with an AF-S Micro Nikkor $105 \mathrm{~mm}$ Nikon objective. Each close-up is recording a $4 \mathrm{~cm} \times 3 \mathrm{~cm}$ area of the painting. The images are then stitched as a panorama view with PTGui software. These photographs have been enriched by X-ray radiography and infrared reflectography images. Additionally, the painting surface has been examined with a digital microscope (Dino-Lite).

In order to obtain further details on the hidden composition and to get a better understanding of the pigments distribution through elemental maps, X-ray fluorescence (XRF) spectroscopy was used in macro scanning mode (MA-XRF). The XRF scan of the whole painting has been completed in approximately $8 \mathrm{~h}$ by using the CEA translation stage and homemade XRF system [6,7], made of a Moxtek Magnum X-ray tube $(50 \mathrm{kV})$ (with a Ag anode), a detector X-123SDD Amptek $\left(25 \mathrm{~mm}^{2}\right)$, with a resolution of $130 \mathrm{eV}$ at $5.9 \mathrm{keV}$. Scanning step was set to $1 \mathrm{~mm}$, speed to $3 \mathrm{~mm} / \mathrm{s}$. X-ray tube was set to a voltage of $40 \mathrm{kV}$ and a current of $120 \mu \mathrm{A}$. Spectra were treated in batch mode using PyMCA [8], allowing separation of the signals from the different chemical elements.

The analyses by Raman spectroscopy (RS) were performed with the Enwave Optronics setup (portable Raman analyzer I-Dual-G), using a laser at $785 \mathrm{~nm}$ [9]. Three Raman spectra were acquired for each of the twelve investigated sites, with the lowest laser power necessary to obtain valuable results (ca. $30 \mathrm{~mW}$ ). The recorded spectra were treated using GRAMS . Data and images were all acquired on the museum site thanks to the CEA mobile lab.

\section{Results and discussion}

The IRR and XRR images recorded for La toile de Pénélope, (Fig. 1) revealed straightaway the presence of two woman's feet beneath the visible portrait. The discovered feet and the way they are displayed, undeniably appear connected to L'évidence éternelle, a truncated female nude composed of five separate small canvases, Magritte first painted early on his career (RMCR n ${ }^{\circ} 327$ [10]) and reproduced twice afterwards (Fig. 2).

The prototype executed in 1930, possibly inspired by Salvador Dali's portraits enclosed in human body shapes, shows a truncated nude of Georgette Magritte, painted in a three-quarter view (Fig. 2a) [10]. In 1948, Magritte completed another version of the work in which the model (still not identified) is portrayed in a frontal view (Fig. 2b) [11]. We know from Sylvester that a third and last variant of L'évidence éternelle was attempted by Magritte in 1954 [4]. However, the entire completion of this late version remained uncertain since, until recently, only three canvases have been traced (Fig. 2c): the face, the breast and the knees. The canvas of the face corresponds to a small woman's portrait subsequently titled La ressemblance, and stayed with Magritte until his death (Fig. 3a). Unfortunately, its model, a young blond woman had not been 
a
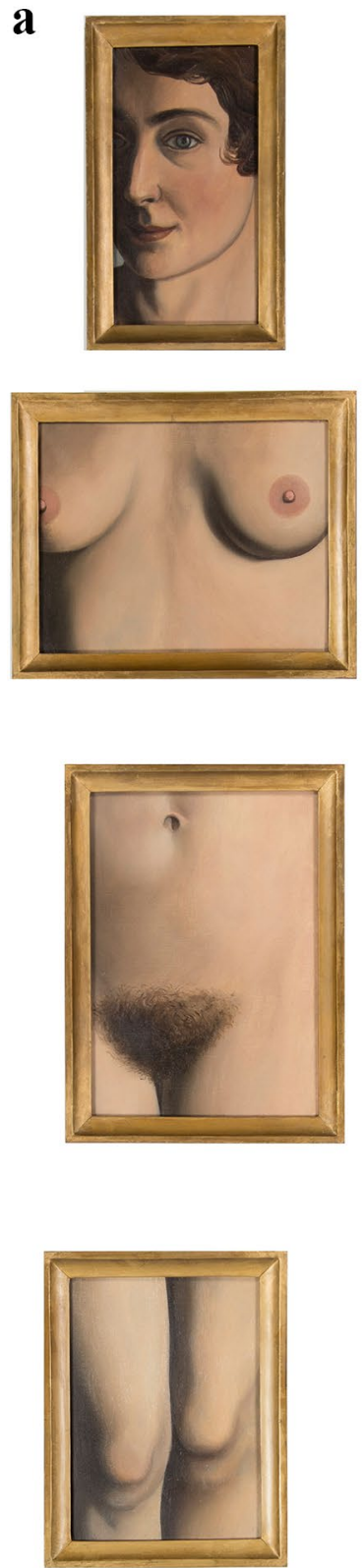

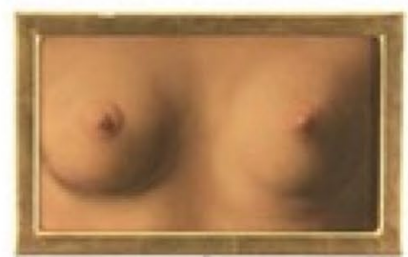

b

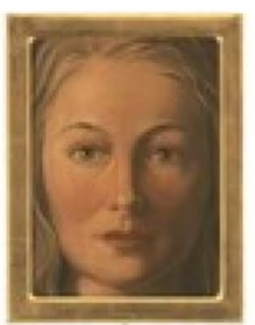

C
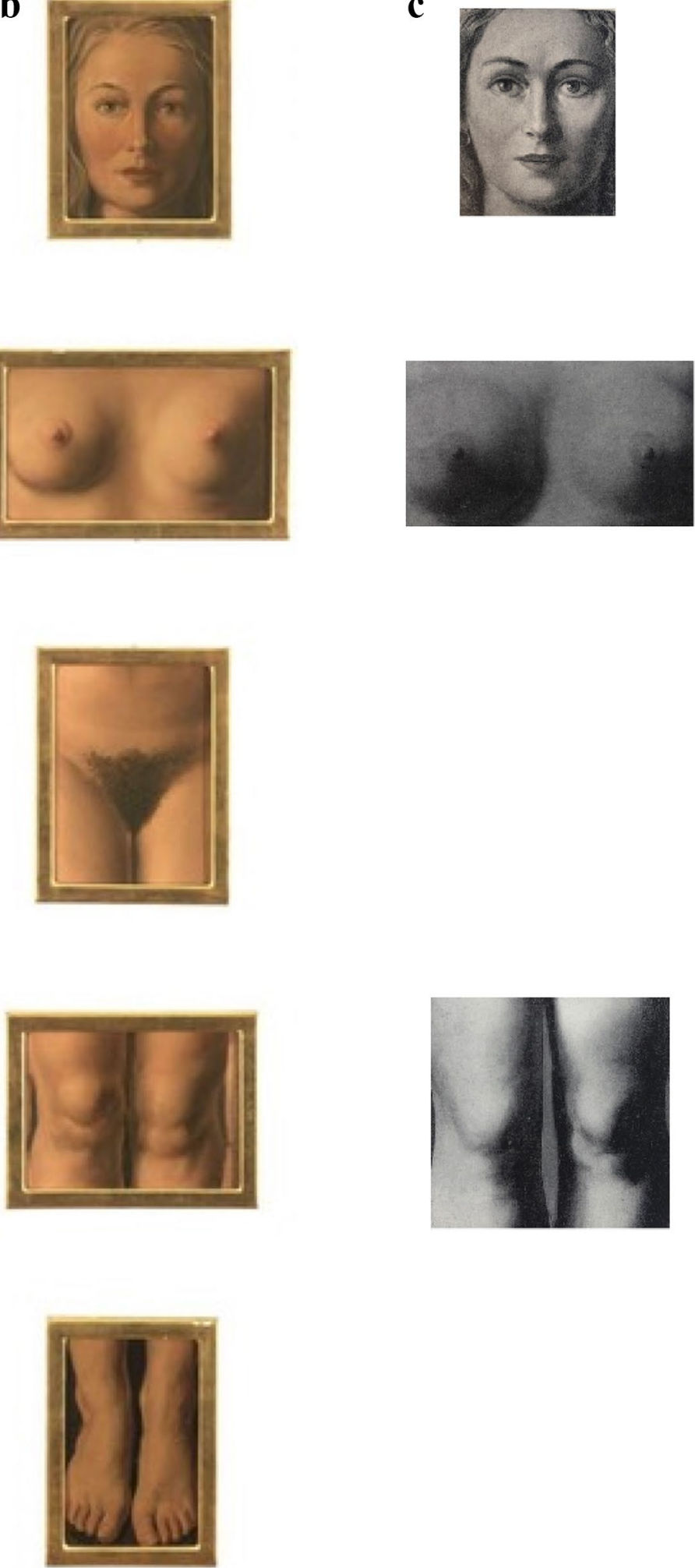

Fig. 2 L'évidence éternelle. a L'évidence éternelle, 1930, oil on five canvases, $22 \times 12,19 \times 24,27 \times 19,22 \times 16,22 \times 12, \mathrm{RMCR}^{\circ} 327$ [10] @Charly Herscovici, Belgium. b L'évidence éternelle, 1948, oil on five canvases, $25.5 \times 19.5,19.3 \times 32,27 \times 20.2,20.5 \times 26.6,26 \times 18, \mathrm{RMCR} n^{\circ} 640$ [1 1] oCharly Herscovici, Belgium. c Lévidence éternelle, 1954, oil on canvases, $20.5 \times 15.6,16 \times 28,21 \times 20$, RMCR n 807 [4] @Charly Herscovici, Belgium 
$\mathbf{a}$

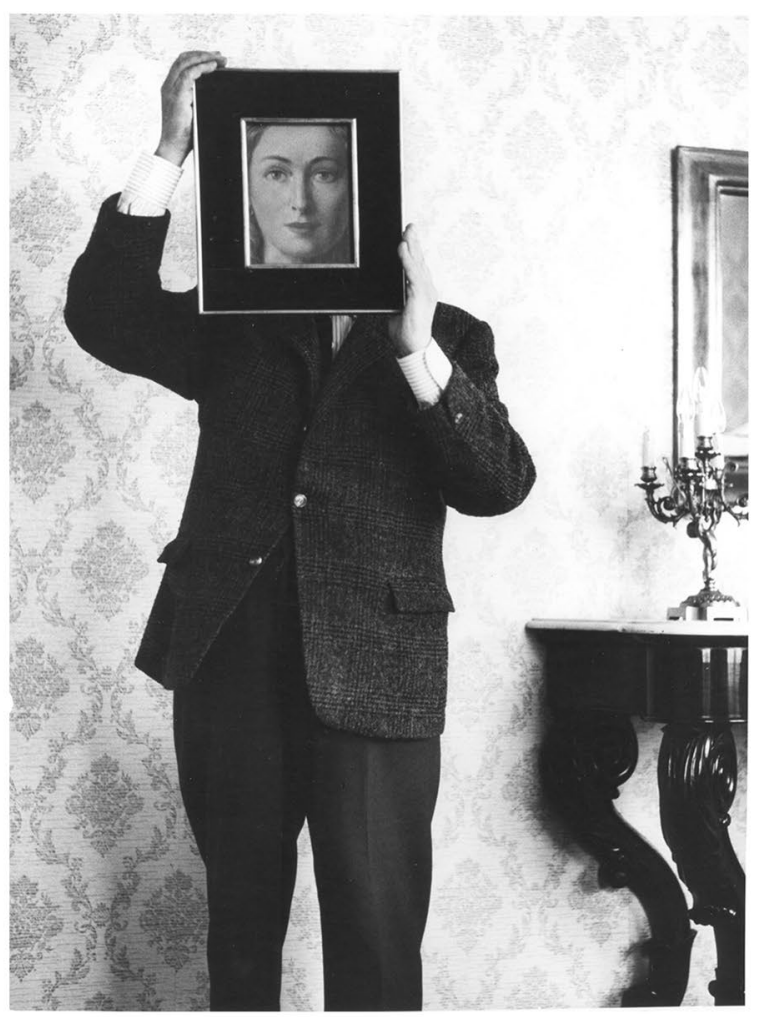

b

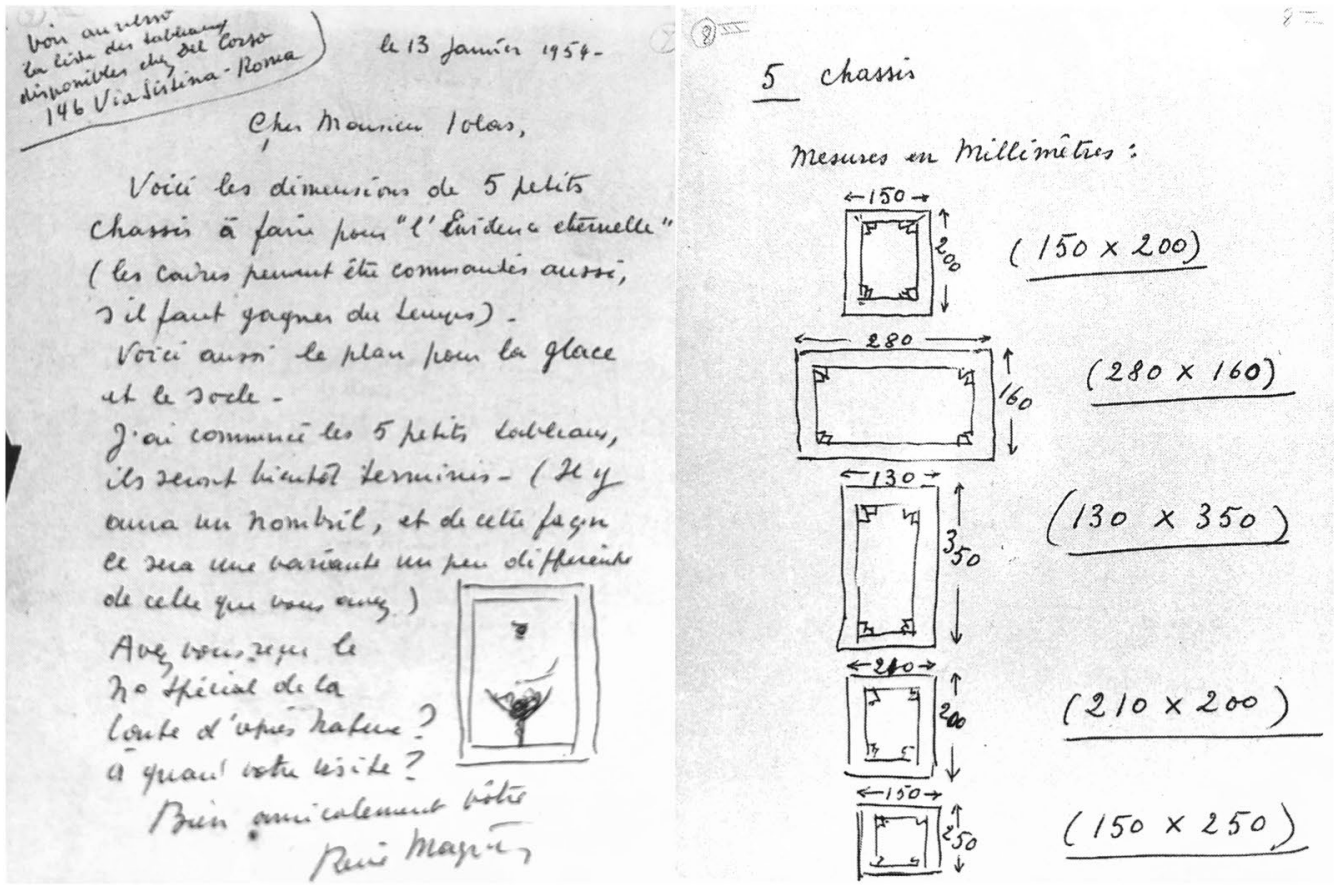

Fig. 3 La ressemblance. a René Magritte posing with La ressemblance in the Mimosas house, in 1954, MRBAB/AACB, inv. 39739 @Charly Herscovici, Belgium. b Project draft of L'évidence éternelle enclosed with a letter Magritte sent to Alexander lolas in 1954 (Magritte archive, The Menil Foundation, Houston) 
identified. The artist offered the canvas of the breast and the one of the knees to Suzi Gablik, a young American author who lived with the Magrittes for eight months in 1960 [12]. Gablik kept the canvas of the knees and sold the one of the breast to Robert Rauschenberg [4].

The subject and the framing of the picture found beneath La toile de Pénélope, but equally its size leave little doubt about its provenance. Like the face, the breast and the knees belonging to the 1954 variant, the discovered feet are represented in a frontal view. Moreover, the canvas dimensions $(24.6 \times 14.8 \mathrm{~cm})$ perfectly match with the stretcher format ascribed to the feet part $(25 \times 15$ $\mathrm{cm})$ in the project draft of Lévidence éternelle from 1954 (Fig. 3b) [4].

The underlying purple layer, punctually visible on the right edge of the painting (Fig. 4a), can be reasonably considered as the background color behind the feet. Indeed, the observed purple color perfectly tones with the background color found in the part of the knees (Fig. 4b). In the light of this outcome, the purple signature affixed in the upper right corner of La toile de Pénélope (Fig. 5a) can be seen as a deliberate reminiscence of the sacrificed picture.

The examination of the painting surface with raking light unveiled Magritte's signature from the lost picture in the lower left corner (Fig. 5b). Although the third canvas that should contain the navel is still missing, the discovery of the fifth part containg a signature strongly indicates that Magritte would have actually painted a navel part as well and that this variant was once a complete set.

The Raman measurements performed on the purple under layer unscathed by the current brown background allowed the identification of Ultramarine, vermilion, lead white and carbon black. In addition, the MA-XRF analysis of the whole painting permitted the identification
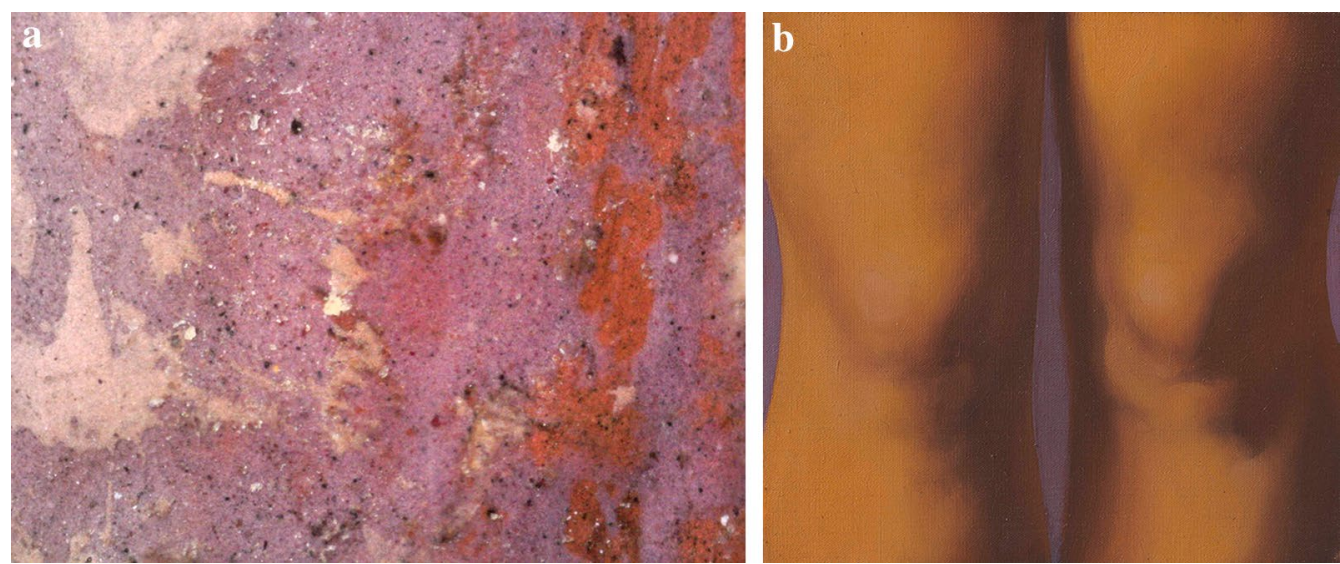

Fig. 4 The background. a Purple under layer punctually visible on the right edge (magnification $\times 50$ ) and originating from the previous background colour. The related purple shade has been achieved by mixing several pigments, including Vermilion, ultramarine, lead white and carbon black. b Part of the knees $(21 \times 20 \mathrm{~cm})$ from the 1954 version of L'évidence éternelle @Charly Herscovici, Belgium
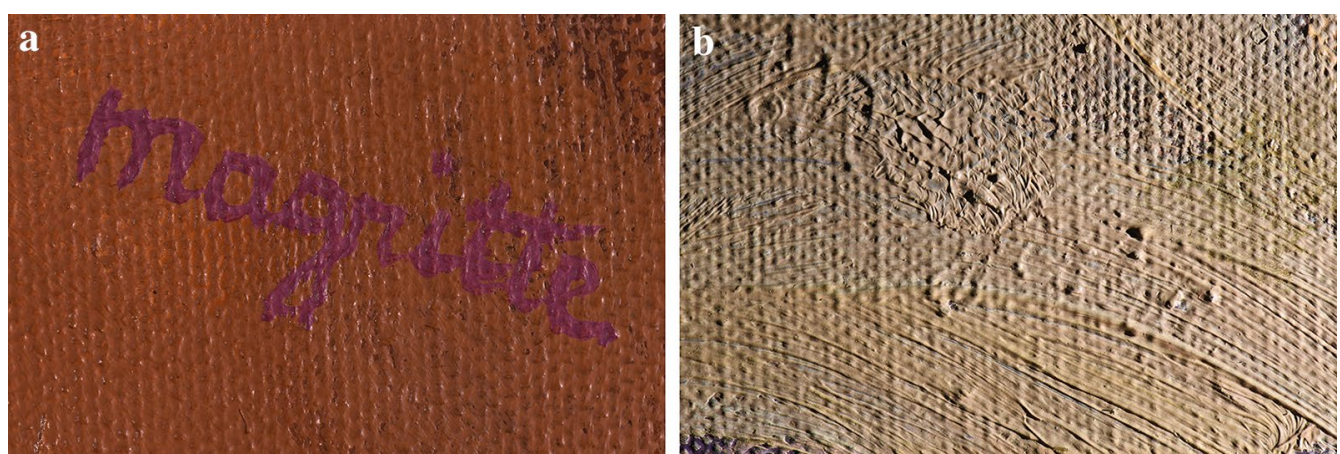

Fig. 5 Signature. a Current purple signature affixed in the upper right corner. b Underlying signature from the feet part of L'évidence éternelle (1954) visible with raking light in the lower left corner 
of inorganic pigments originating from both the visible image and the hidden composition. The distribution maps recorded for $\mathrm{Hg}$ and $\mathrm{Pb}$ (Fig. 6) support the presence of Vermilion and lead white in the overall background color enclosing the feet. The Hg scan provided further information on the lost image since it made visible the former signature lying just below the left foot as a shadow. Concerning the feet themselves, the MA-XRF scans of the $\mathrm{Zn}, \mathrm{Fe}$ and $\mathrm{Ca}$ elements (Fig. 6) indicate flesh tones based on zinc white and iron oxide/hydroxide pigment(s) with Ca contents.

Like reported for several other Magritte's oil paintings and observed in MA-XRF scan of the painting side, the present canvas has been primed with two separate ground layers, a first one based on lead white and a second one based on zinc white [2,13-16].

The MA-XRF results (Fig. 6) and the Raman spectra related to the visible portrait led to the identification of titanium white (anatase), barite, strontium sulfide, zinc white, vermilion, iron oxides with calcium contents, ivory black and ultramarine. The white pigment predominantly used for painting La toile de Pénélope is titanium white (anatase), associated with barite and strontium sulfide.
However, zinc white has been equally identified from the painting surface, chiefly in the flesh tones. Besides titanium white and zinc white, the flesh tones involve iron oxides pigments with calcium contents, vermilion and ultramarine. The brown background and the brown hair have in common high contents of iron oxides and titanium white (admixed with barite and strontium sulfide). The use of vermillion is prominent only in the nose and in the lips.

A colorized reconstruction of the feet part, built on the basis of the overall information collected in the present study, is proposed in Fig. 7. Color hue has been identified by looking at the right edge of the painting while contours and shadows have been obtained by looking at the $\mathrm{Zn}$ and $\mathrm{Pb}$ MA-XRF scans (Fig. 6).

\section{Conclusions}

The woman's feet revealed through the IRR and XRR images leave little doubt about the identity of the composition lying beneath La toile de Pénélope. All the more, so do the dimensions of the canvas which totally match the format ascribed to the feet part in the 1954 project
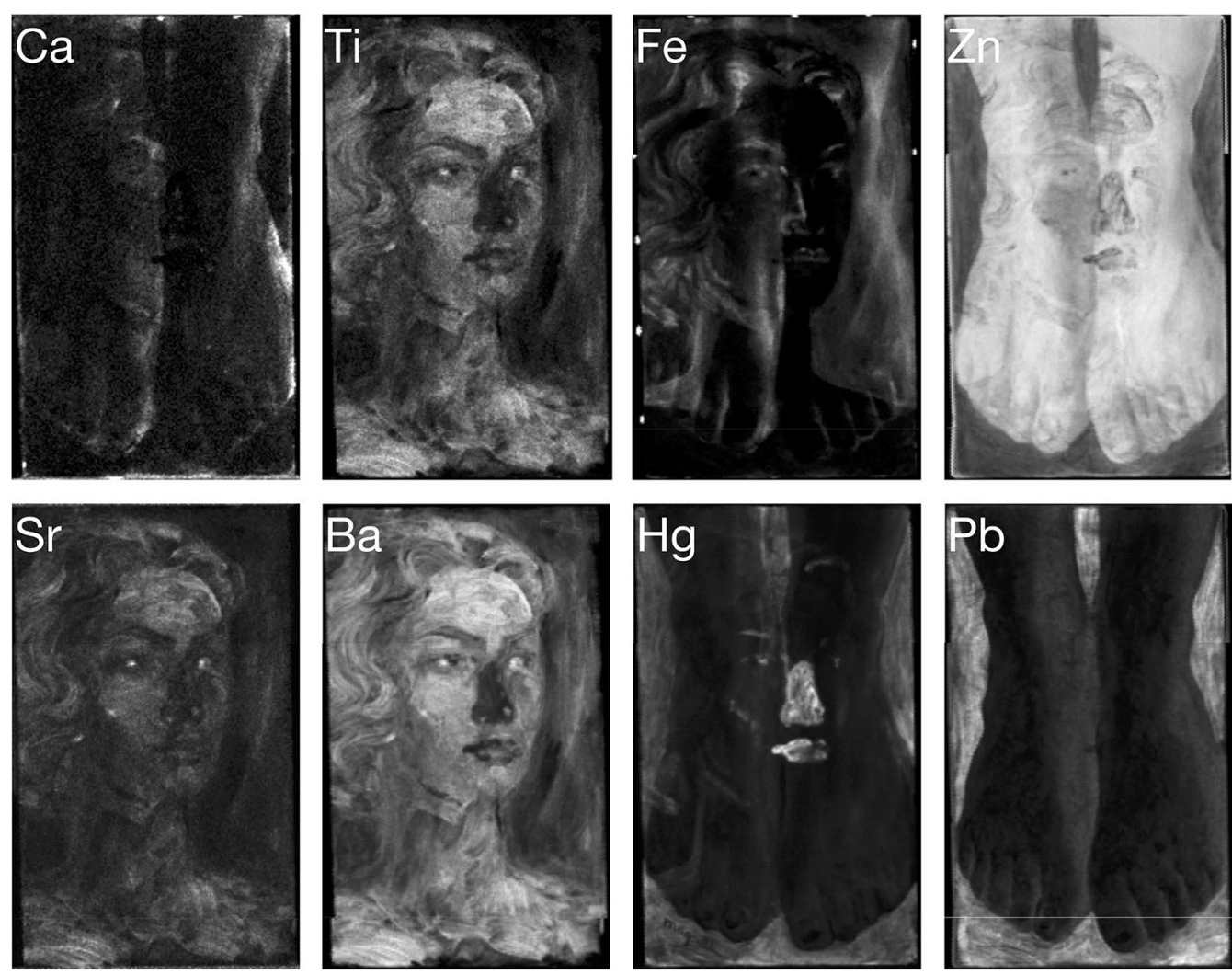

Fig. 6 MA-XRF. MA-XRF maps showing the distribution of Calcium (Ca K-ray), Titanium (Ti, K-ray), Iron (Fe, K-ray), Zinc (Zn, K-ray), Strontium (Sr, K-ray), Baryum (Ba, L-ray), Mercury ( $\mathrm{Hg}, \mathrm{L}-\mathrm{ray})$ and Lead ( $\mathrm{Pb}, \mathrm{L}$-ray) for the whole painting. The grey scale corresponds to the intensity of the signal of each element, black being the minimum of the signal, white, the maximum 


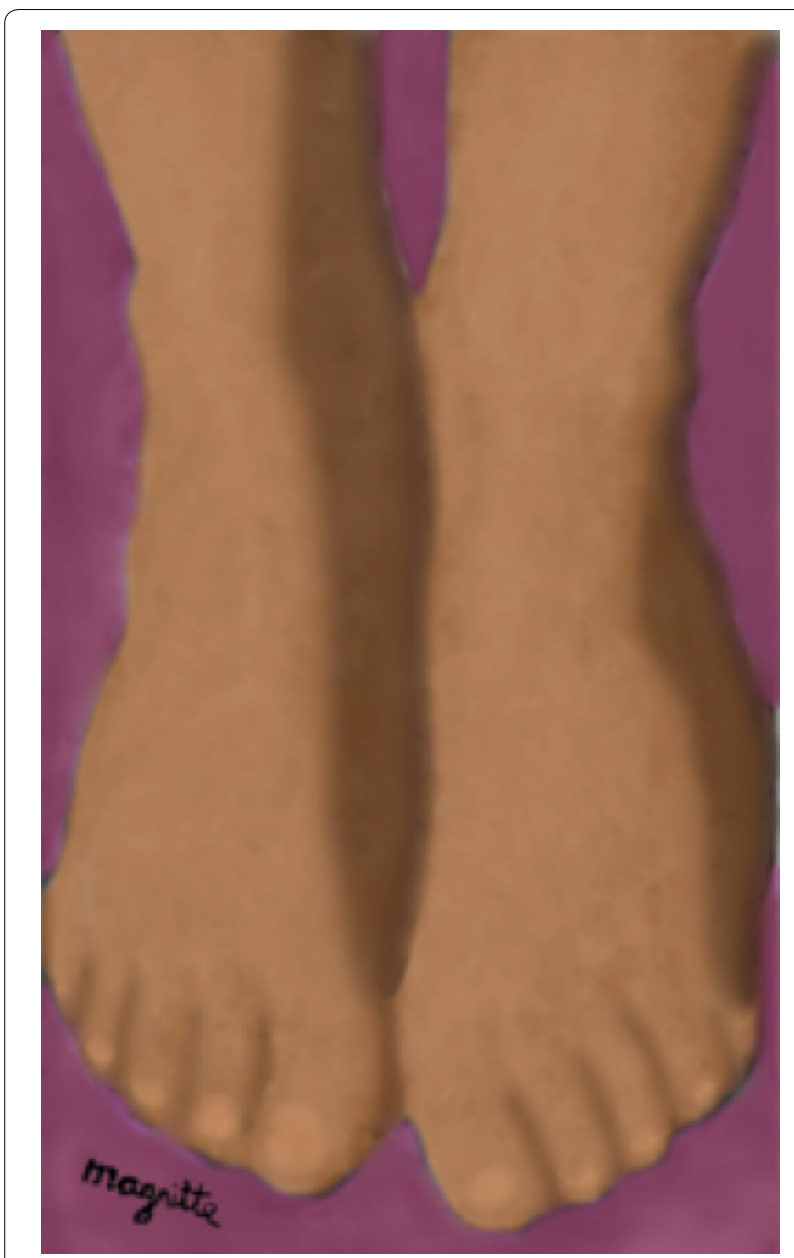

Fig. 7 Virtual reconstruction. Virtual colorized reconstruction of the feet part from L'évidence éternelle (1954), built on the basis of the XRR and IRR images, the MA-XRF results, the examination of the painting subsurface through digital microscopy and the chromatic range of the related knees part

draft Magritte made of Lévidence éternelle. Like the face, the breast and the knees, the feet from the 1954 variant have been portrayed in a frontal view. The model's pose is therefore much closer to the 1948 version than to the prototype, within Georgette Magritte which was painted in a three-quarter view.

Because it perfectly matches with the purple background of the knees, the purple under layer visible in some places on the right edge of La toile de Pénélope most probably corresponds to the background color of the feet. In the light of this outcome, the purple signature in the upper right corner of La toile de Pénélope, appears as a reminiscence of the sacrificed composition.

With regards to the last missing canvas from Lévidence éternelle of 1954, the discovery of the signed feet part tends to evidence Magritte likely did complete the painting of the navel as well.

\section{Acknowledgements}

The authors sincerely thank Michel Draguet, General Director of the RMFAB for his commitment that greatly assisted this research. The authors would like also to express their gratitude to Ludovic Godfrin, Modern painting collection keeper at the RMFAB, for his technical assistance.

\section{Authors' contributions}

$\mathrm{CD}, \mathrm{EH}$ and DS have realized the in situ measurements (imaging, XRF and Raman), CD, DS and FV have interpreted the results of the analysis. All authors read and approved the final manuscript.

\section{Funding}

This project has received funding from the University of Liège (Belgium).

\section{Availability of data and materials}

The datasets used and/or analysed during the current study are available from the corresponding author on reasonable request.

\section{Competing interests}

The authors declare that they have no competing interests.

\section{Author details}

1 UR Art, Archéologie, Patrimoine, Université de Liège, 4000 Liege, Belgium.

${ }^{2}$ Royal Museums of Fine Arts of Belgium, 1000 Brussels, Belgium.

Received: 23 Auqust 2019 Accepted: 6 November 2019

Published online: 21 November 2019

\section{References}

1. Sylvester D. Magritte. Arles: Actes Sud Beaux-Arts; 2009.

2. Defeyt C, Herens E, Leen F, Vandepitte F, Strivay D. Discovery and multianalytical study of the last missing quarter from rené magritte's la pose enchantée. Herit Sci. 2018;6(1):33.

3. Defeyt C, Vandepitte F, Herens E, Strivay D. Insight in René Magritte's reused paintings. Talk at Technart19, Brugge May 7-10; 2019.

4. Sylvester D, Whitfield S, Raeburn M. René Magritte-Catalogue Raisonné, tome 3: oil paintings, objects and bronzes 1949-1967. Paris: Flammarion; 1994

5. Strivay D, Clar M, Rakkaa S, Hocquet F-P, Defeyt C. Development of a translation stage for in situ noninvasive analysis and high-resolution imaging. Appl Phys A. 2016;122(11):950.

6. Hocquet F-P, Garnir H-P, Marchal A, Clar M, Oger C, Strivay D. A remote controlled xrf system for field analysis of cultural heritage objects. X-Ray Spectrom. 2008:37(4):304-8.

7. Hocquet F-P, Calvo del Castillo H, Cervera Xicotencatl A, Bourgeois C, Oger C, Marchal A, Clar M, Rakkaa S, Micha E, Strivay D. Elemental 2d imaging of paintings with a mobile edxrf system. Anal Bioanal Chem. 2011;399(9):3109-16.

8. Solé VA, Papillon E, Cotte M, Walter P, Susini J. A multiplatform code for the analysis of energy-dispersive $x$-ray fluorescence spectra. Spectrochim Acta Part B At Spectrosc. 2007;62(1):63-8.

9. Lauwers D, Hutado AG, Tanevska V, Moens L, Bersani D, Vandenabeele P. Characterisation of a portable raman spectrometer for in situ analysis of art objects. Spectrochim Acta Part A Mol Biomol Spectrosc. 2014;118:294-301.

10. Sylvester $D$, Whitfield S. René Magritte—Catalogue Raisonné, tome 1: oil paintings 1916-1930. Paris: Flammarion; 1992.

11. Sylvester $D$, Whitfield S. René Magritte—Catalogue Raisonné, tome 2: oil paintings and objects 1931-1948. Paris: Flammarion; 1993.

12. Gablik S. Magritte. Bruxelles: Cosmos monographies; 1978.

13. Van der Snickt G, Martins A, Delaney J, Janssens K, Zeibel J, Duffy M, McGlinchey C, Driel BV, Dik J. Exploring a hidden painting below the surface of René Magritte's Le Portrait. Appl Spectrosc. 2016;70(1):57-67.

14. da Silva AT, Legrand S, Van der Snickt G, Featherstone R, Janssens K, Bottinelli $G$. Ma-xrf imaging on rené magritte's la condition humaine: insights 
into the artist's palette and technique and the discovery of a third quarter of la pose enchantée. Herit Sci. 2017;5(1):37.

15. Duffy M, Martins A, Boon JJ. Issues in contemporary oil paint. In: van den Berg KJ, Burnstock A, de Keijzer M, Krueger J, Learner T, de Tagle A, Heydenreich G. (eds.) Metal soaps and visual changes in a painting by René Magritte-the Menaced Assassin, 1927. Cham: Springer; 2014. p. 197-203.

16. Defeyt C, Vandepitte F, Mazurek J, Herens E, Strivay D. Conservation of modern oil paintings. In: van den Berg K, Bonaduce I, Burnstock A,
Ormsby B, Scharff M, Carlyle L, Heydenreich G, Keune K. (eds.) Investigation on the speckles syndrome affecting late 1920s oil paintings by René Magritte, Chap. 19. Cham: Springer; 2019. p. 180-8.

\section{Publisher's Note}

Springer Nature remains neutral with regard to jurisdictional claims in published maps and institutional affiliations.

\section{Submit your manuscript to a SpringerOpen ${ }^{\circ}$ journal and benefit from:}

- Convenient online submission

- Rigorous peer review

- Open access: articles freely available online

- High visibility within the field

Retaining the copyright to your article

Submit your next manuscript at $\boldsymbol{\nabla}$ springeropen.com 